\title{
Biological and Molecular Variability Among High Plains virus Isolates
}

Dallas L. Seifers, Professor, Kansas State University, Agricultural Research Center-Hays 67601-9228; Y.-M. She, Department of Physics, University of Manitoba, Winnipeg, Manitoba, Canada; Tom L. Harvey, Professor, Department of Entomology, Kansas State University, Manhattan 66506; T. J. Martin, Professor, Kansas State University, Agricultural Research Center-Hays; S. Haber, Cereal Research Centre, Agriculture \& Agri-Food Canada, Winnipeg, Manitoba, Canada; W. Ens and K. G. Standing, Department of Physics, University of Manitoba, Winnipeg; and Raymond Louie, United States Department of Agriculture-Agricultural Research Service and D. T. Gordon, Professor, Emeritus, Department of Plant Pathology, The Ohio State University, Wooster 44691

\begin{abstract}
Seifers, D. L., She, Y.-M., Harvey, T. L., Martin, T. J., Haber, S., Ens, W., Standing, K. G., Louie, R., and Gordon, D. T. 2004. Biological and molecular variability among High Plains virus isolates. Plant Dis. 88:824-829.

The High Plains virus (HPV), vectored by the wheat curl mite (WCM) (Aceria tosichella), causes a severe disease of maize (Zea mays) in the U. S. High Plains. In the present study, five HPV isolates from five states were separated from co-infecting Wheat streak mosaic virus and their molecular and biological variability studied. Molecular studies involved time-of-flight mass spectrometry (TOFMS) to determine amino acid sequence variability of the 32-kDa nucleoprotein (32 np) of the isolates. Biological studies involved testing the ability of the five HPV isolates to infect a maize line previously shown to have resistance. Inoculations of the HPV isolates were conducted using vascular puncture inoculation (VPI) and viruliferous WCM. TOFMS analyses demonstrated an 18-amino acid sequence in the isolates at the N-terminus of the $32 \mathrm{np}$, the presence of amino acid sequence differences among the isolates, and variability among amino acid sequences of the $32 \mathrm{np}$ of some isolates. Three of the five HPV isolates infected the resistant maize inbred, B73, using VPI, and two of the same three HPV isolates infected this line using WCM inoculation, albeit low numbers of plants were infected by each technique.
\end{abstract}

In 1993, a previously unknown pathogen was identified infecting maize (Zea mays L.) from the U. S. High Plains states of Colorado, Idaho, Kansas, and Texas (4). The pathogen was associated with a 32$\mathrm{kDa}$ nucleoprotein (32 $\mathrm{np}$ ) and antiserum prepared to this protein preferentially reacted to it in enzyme-linked immunosorbent assay (ELISA) and Western blot assays (5). Thread-like virus particles from symptomatic maize leaves infected with this pathogen also were observed by electron microscopy (1). These particles were preferentially labeled when probed in immunogold-labeling experiments using

Corresponding author: D. L. Seifers

E-mail: dseifers@ksu.edu

Contribution No. 04-202-J from the Kansas Agricultural Experiment Station. Research in Kansas and Ohio was supported in part by a grant from Pioneer Hybrid International, Inc. Johnston, IA 50131. Research in Manitoba was supported by grants from the U.S. National Institutes of Health (GM 59240) and from NSERC (Canada).

High Plains virus 32-kDa nucleoprotein sequences deposited as Swiss Prot. Accession Nos.: P83549, P83550, P83664, P83665, and P83666.

Accepted for publication 30 March 2004.

Publication no. D-2004-0601-02R

(C) 2004 The American Phytopathological Society antiserum to the $32 \mathrm{np}$. In this same study, double-membrane bodies were observed in thin sections of virus-infected cells. When probed with the same antiserum, the center, but not the membranes of these bodies, were decorated with the gold-labeled antibodies.

In previous studies, several doublestranded (ds)RNA segments were identified from virus-infected tissue (4). The nucleotide sequence of segment RNA3 was determined and deposited in the GenBank (accession no. U60141). These data gave evidence for a viral identity of the pathogen, which was named the High Plains virus (HPV) (5).

HPV is transmitted by the wheat curl mite (WCM; Aceria tosichella Keifer; 16,22 ) and mechanically by vascular puncture inoculation (VPI; 11,15). HPV is not mechanically transmitted by leaf-rub procedures (5). In addition, it has been demonstrated that different sources of WCM transmit HPV isolates differentially (15). Plants naturally infected in the field by HPV vectored by WCM include: wheat (Triticum aestivum L.), barley (Hordeum vulgare L.), maize, yellow foxtail (Setaria glauca (L.) Beauv.), and green foxtail ( $S$. viridis (L.) Beauv.) (17). The incidence of HPV infection of wheat in fields declined with distance from infected volunteer wheat, as expected for virus vectored by the WCM (16). The latter was found to co- transmit Wheat streak mosaic virus (WSMV) and HPV in the field (16). The HPV has been shown to be seed transmitted in sweet corn (3).

Resistance to systemic spread of a Texas isolate of HPV contaminated with WSMV has been reported for certain maize lines $(12,13)$. However, the effect of single infection by HPV without WSMV on the efficacy of this resistance has not been elucidated. Likewise, variation in biological and molecular characteristics among HPV isolates uncontaminated with WSMV from different geographical locations has not been investigated. Therefore, our goals were to (i) determine the variation in amino acid sequence of the $32 \mathrm{np}$ of HPV isolates from different geographical locations, (ii) determine the ability of these isolates to infect maize resistant to HPV when uncontaminated with WSMV, and (iii) determine variation in transmission of isolates by VPI and viruliferous WCM. The sequences for the ID97 (P83549) and KS97 (P83550) HPV isolates have been published previously (20).

\section{MATERIALS AND METHODS}

Source and maintenance of WCM and infestation of plants. A Nebraska WCM source (provided by Gary Hein, University of Nebraska, Scottsbluff) obtained from wheat was used in these studies. This WCM source was efficient in vectoring HPV (15). The WCM collection originally was viruliferous for both WSMV and HPV (15). Nonviruliferous WCM were obtained by raising adults from eggs and increasing them on caged 'Tomahawk' wheat as described (15).

Sources and maintenance of HPV isolates. The HPV isolates were obtained from maize from Colorado (isolate CO96; Bob Hammond, Fruita, CO, 1996), Idaho (isolate ID97; Bob Forster, 1997), Kansas (isolate KS96; Ellis County, 1996), Texas (isolate TX96; C. Rush, Texas A\&M, University, Bushland, TX, 1996), and Utah (isolate UT96; S. Jensen from sample received from Utah, 1996). The HPV isolates were maintained in maize by VPI of 'Spirit' corn kernels as described (15). Source plants were covered with cages as described (16) before and after inoculation to prevent infestation with WCM. Before 
all VPI transfers of HPV isolates and following their establishment in Spirit, infected plants were tested by ELISA as described below against HPV and WSMV antiserum, respectively, to verify isolate purity.

Sources of antiserum. Antiserum to HPV was processed and used as reported (16). Antisera to WSMV was prepared as described (14).

Indirect ELISA. The procedure for the indirect ELISA was described (16) and is as follows. Leaf tissue was ground at 1:30 (wt/vol dilution) in $0.05 \mathrm{M}$ carbonate buffer, pH 9.6 (coating buffer) (2), and antiserum to HPV was used at a $1: 50,000$ dilution prepared from a 1:100 cross-absorbed stock in ELISA blocking buffer (16). The anti-rabbit antibody alkalinephosphatase conjugate $(1: 3,000 \mathrm{vol} / \mathrm{vol})$ (Sigma-Aldrich, St. Louis) and WSMV antibodies $(1: 1,000 \mathrm{vol} / \mathrm{vol}$ from a $1 \mathrm{mg} / \mathrm{ml}$ stock solution) were diluted using ELISA blocking buffer. All samples, antibody solutions, and substrate solutions were used at a 200- $\mu$ l volume. Substrate (pnitrophenyl phosphate, $0.714 \mathrm{mg} / \mathrm{ml}$ ) in substrate buffer (2) was added to plates, which were incubated at room temperature, and the absorbance at $405 \mathrm{~nm}$ was measured after 30 min (Titertek Mulitskan Microelisa Plate Reader; Flow Laboratories, Inc., McLean, VA). Positive controls consisted of frozen WSMV isolate Sidney 81 and the KS96 HPV isolate and negative controls were healthy plants of the appropriate species. The minimum absorbance threshold value for WSMV was 1.8 times the healthy control. This value was based on results from a preliminary experiment in which an extract from maize infected by both HPV and WSMV had an ELISA absorbance value for WSMV 1.9 times the equivalent healthy control and was infective to wheat when leaf-rub inoculated (15). For HPV, a positive absorbance threshold value was 0.054 . This value was based on results from a Western-blot analysis that detected the 32 $\mathrm{np}$ in tissue that had an absorbance value as low as 0.054 in ELISA (17).

Minipurification and sodium dodecyl sulfate-polyacrylamide gel electrophoresis of proteins. The proteins from HPVinfected Spirit corn plants were extracted and minipurified following the procedure of Lane (9). Relative molecular masses were calculated using a densitometer to determine electrophoretic mobility compared with protein standards (14). The method of Laemmli (8) was used for sodium dodecyl sulfate-polyacrylamide gel electrophoresis (SDS-PAGE). Electrophoresis was carried out in a $10 \%$ gel, 0.75 mm thick, using a Hoefer SE 600 apparatus for $2.5 \mathrm{~h}(60 \mathrm{~mA})$. Proteins were stained with Coomassie blue $(0.125 \%$ Coomassie blue R-250, 30\% methanol, and $10 \%$ acetic acid). Mass standards were: myosin, rabbit muscle $(205 \mathrm{kDa}) ; \beta$ - galactosidase (116 kDa); phosphorylase b, rabbit muscle ( $97.5 \mathrm{kDa})$; albumin, bovine (66 kDa); albumin, egg (45 kDa); and carbonic anhydrase, bovine erythrocyte (29 $\mathrm{kDa}$ ). Stained bands corresponding to the position of the $32 \mathrm{np}$ were excised from the gels.

Time-of-flight mass spectrometry. HPV-specific $32 \mathrm{np}$ were sent to the University of Manitoba, where masses and amino acid sequences were determined by time-of-flight mass spectrometry (TOFMS), using MS and MS/MS measurements. The excised $32 \mathrm{np}$ band from each gel was digested with endoproteinases as described (21), using sequencing grade trypsin, LysC, Glu-C, and Asp-N (Roche Diagnostic Corp. (Indianapolis, IN). Digestion was performed on the proteins using either 10 ng of trypsin, $50 \mathrm{ng}$ of Lys-C, or Glu-C, in $25 \mathrm{mM}$ ammonium bicarbonate; or $50 \mathrm{ng}$ of Asp-N in $10 \mathrm{mM}$ Tris- $\mathrm{HCl}$ (pH 7.6) solution.

Derivatization of in-gel digests. For de novo peptide sequencing, $y$-ions from some peptides were produced using sulfonic acid derivatization of the in-gel tryptic digests. The peptides were dehydrated followed by reaction with chlorosulfonylacetyl chloride as described (6). Yield of the sulfonated product was improved by repeating the procedure three times.

MS of peptide amino acid sequences. Samples were analyzed by matrix-assisted laser desorption ionization (MALDI) on a QqTOF mass spectrometer (7) after digestion or chemical modification as described previously (18-20), using 2,5-dihydroxybenzoic acid as the matrix. The MS/MS daughter ion spectra occurred after collision-induced dissociation in the QqTOF collision cell. Peptide sequences then were determined by manual interpretation of the MS and MS/MS measurements, and identified by searching with the MS-Tag, BLAST, or FASTA databases.

VPI of maize. Virus inocula were prepared from Spirit corn infected with HPV isolate, CO96, ID97, KS96, TX96, or UT96 at 21 days post inoculation (DPI). Groups of 100 B73 maize kernels were inoculated by VPI with inoculum from one of the five isolates using the procedure detailed previously (15). Briefly, maize seed was inoculated by placing HPV inoculum on the embryo side of each kernel, after which the kernel was inoculated through the inoculum and the pericarp covering of the scutellum with five minuten pins affixed to an engraver. The seed then were incubated at $30^{\circ} \mathrm{C}$ in a moist environment for $48 \mathrm{~h}$ and then planted into soil. Following VPI of 100 corn seed for each HPV isolate, the seed were planted into 30-by-50-cm soil-filled metal flats with 10 seed per row. Flats were randomized in a greenhouse and held under natural lighting with a temperature range of 22 to $30^{\circ} \mathrm{C}$ during the three experiments. The number of plants with symptoms (spots with mosaic) were recorded at 21 DPI . At this time, the fourth leaf of each plant was tested by ELISA to verify that symptomatic plants were infected with HPV and free of WSMV. Tissues from symptomless plants were bulked for a given treatment and tested by ELISA as described for the symptomatic plants. ELISA reactions of the three experiments were determined visually. Controls consisted of Spirit and B73 kernels inoculated by VPI with extracts from healthy Spirit maize. Spirit kernels were obtained from Rogers Seed Co. (Boise, ID) and those of B73 from Shawn Kaeppler (University of Wiscon$\sin )$.

Percentage data (number of HPV-infected maize plants/number of surviving inoculated plants) were arcsine-transformed before analysis of variance when the range of percentages among treatments was greater than 40 (10). Data presented are numbers of plants and percentages. Significant treatment effects were compared by the Student-Newman-Keul's multiple range test.

Infestation of barley and maize with viruliferous WCM. The WCM were allowed a 24-h acquisition access period on HPV-infected Spirit maize (infected 21 days previously) and then $10 \mathrm{WCM}$ (adults and nymphs) were used to infest each of the barley and maize plants. The acquisition of HPV and infestation of test plants by WCM were as described in detail elsewhere (15). The WCM and HPV source plants and test plants were covered with plastic cages before and after infestation as described previously (16). Controls consisted of WCM fed on healthy maize and then transferred to five barley assay plants. All infected Spirit corn plants used for HPV acquisition were pretested by ELISA at 21 days following VPI using HPV and WSMV antiserum to verify purity of the HPV isolates as described previously (15). Twenty-five barley and maize plants were projected to be infested for each HPV isolate; however, the number of plants infested with viruliferous WCM for each HPV isolate was a function of the numbers that could be recovered from the HPVinfected Spirit acquisition plants. Leaves used for HPV acquisition were usually from a single plant, but sometimes also from more than one plant, depending upon plant size.

In the WCM phase of this research, Westford barley was used as the control because it has been shown previously to be easily infected with HPV using viruliferous WCM (16). Following infestation of the maize and barley assay plants, the WCM were allowed a 24-h inoculation feeding and then all test plants were treated with carbofuran $(27 \mathrm{mg} / \mathrm{liter})$ to kill the WCM. Caged plants were held in a greenhouse under natural lighting with a temperature range of 19 to $31^{\circ} \mathrm{C}$ during the three experiments. 


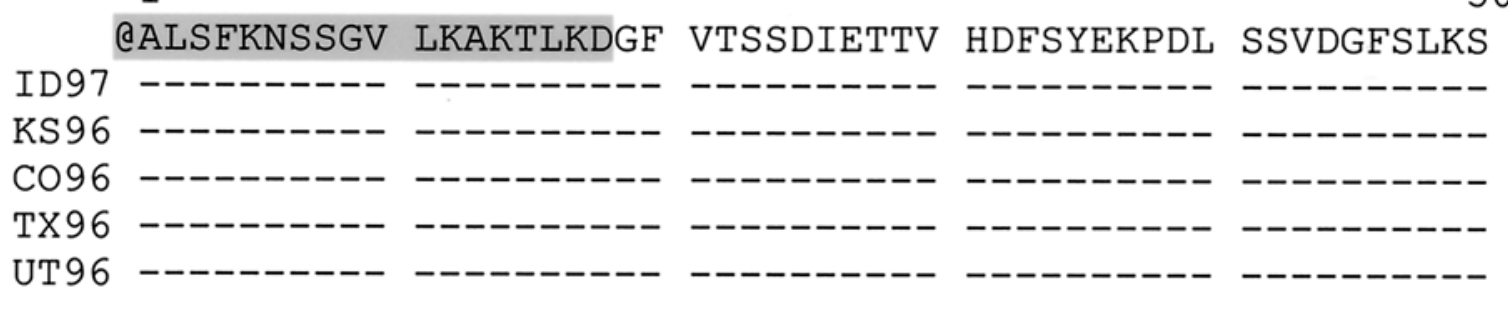

51

100

LLSSDGWHIV VAYQSVTNSE RLNNNKKNNK TQRFKLFTFD IIVIPGLKPN
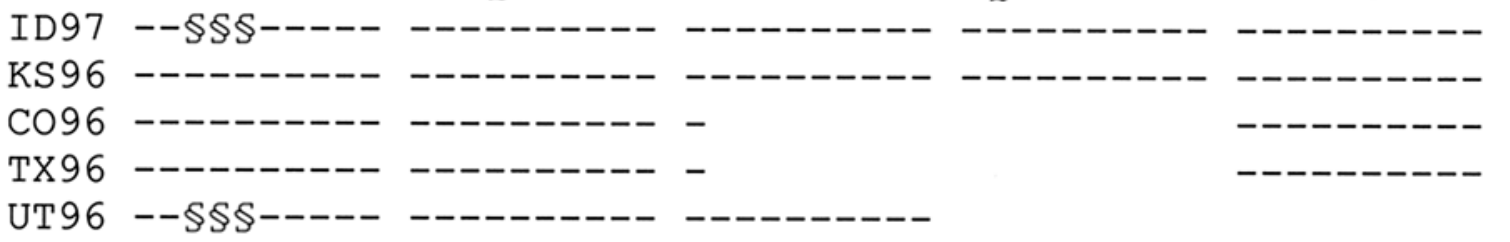

101
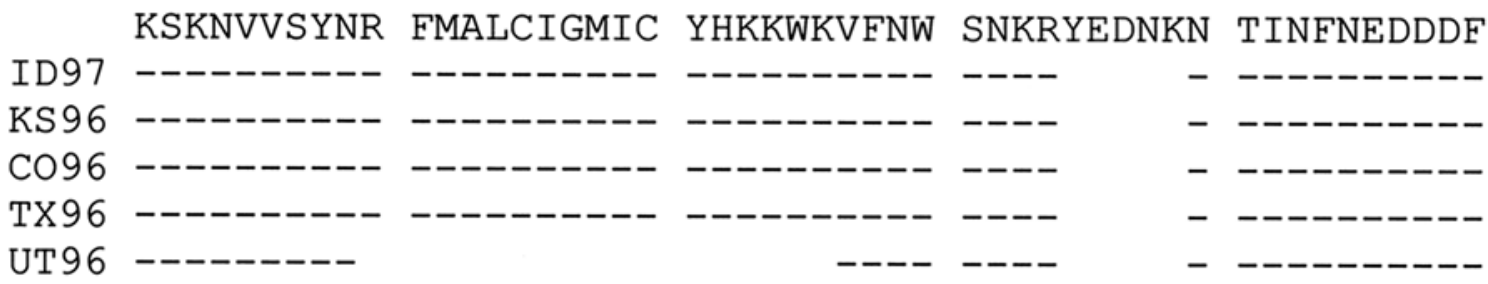

151

MNKLAMSAGF SKEHKYHWFY STGFEYTFDI FPAEVIAMSL FRWSHRVELK

ID97 --------- --
KS96 ---
CO96 ---
TX96 ---
UT96 ---

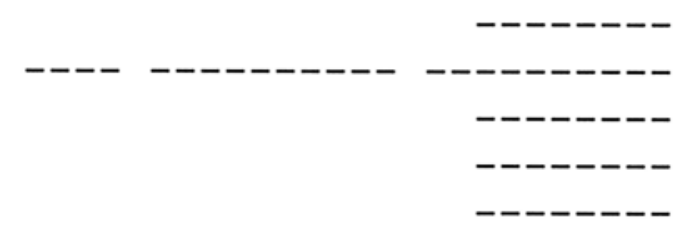

201

\section{IKYEHESDLV APMVRQVTKR GNISDVMDIV GKDIIAKKYE EIVKDRSSIG}

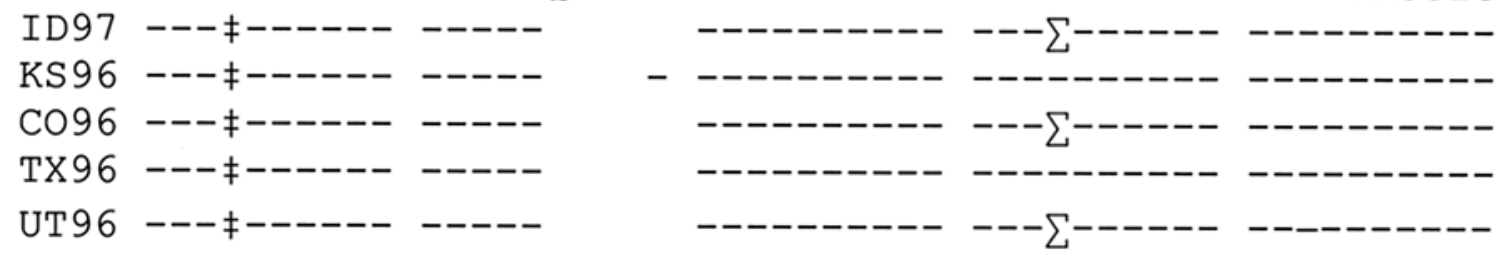

251

IGTKYNDILD EFKDIFNKID SSSLDSTIKN CFNKIDGE

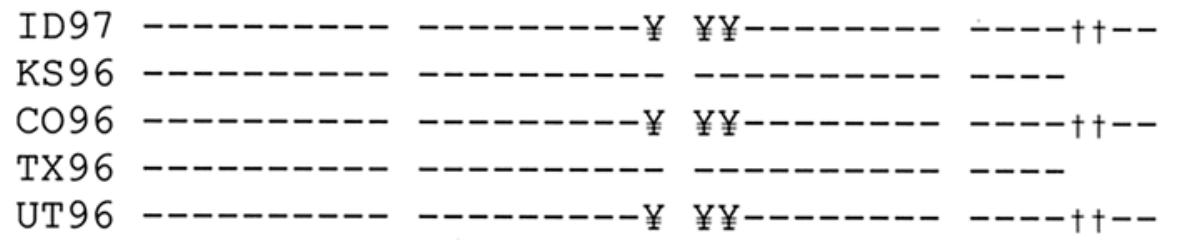

Fig. 1. Amino acid sequences of the 32-kDa nucleoprotein of five isolates of the High Plains virus (HPV) determined by time-of-flight mass spectrometry. The top line shows the amino acid sequence deduced from U60141 (NCBI database accession no. 1407699). The first highlighted 18-amino acid (aa) residues in the sequence of U60141 are not part of the published sequence for this isolate, but were inserted as a spacing device to aid in comparison among the other HPV isolates where this 18-aa tract was determined to be present. Areas within the sequence without dashes or symbols indicate undetermined amino acids; @ means N-terminal acetylation, the numbers refer to amino acid residues, dashed lines in the HPV sequences indicate consensus with U60141. Observed subpopulations in the HPV isolates are: $\S \S=\mathrm{SSD}$ or TSE; $\$=\mathrm{E}, \mathrm{N}$, or D; $\Sigma=\mathrm{I}$ or T; $¥ ¥=\mathrm{DSS}$ or NST; $\dagger \dagger=\mathrm{ID}$ or T. 
HPV transmission to maize and barley test plants was assayed by symptom expression (21 DPI) on leaves 3 and 4 . Symptoms were rated using the following scale: $1=$ no symptoms, $2=$ chlorotic dots and faint mosaic, $3=$ moderate mosaic, and $4=$ severe mosaic with occasional necrotic spots. The fourth leaf of each plant also was tested by ELISA using HPV and WSMV antiserum to confirm HPV infection and the absence of WSMV infection. The ID97 and UT96 HPV isolates were lost prior to the onset of the WCM experiments.

Percentage data (number of HPV-infected maize and barley assay plants/ number infested) were arcsine-transformed before analysis of variance when the range of percentages among treatments was greater than 40 (10), and difference among means were compared using a simple least significant difference test. Data presented are numbers of plants and percentages. Significant treatment effects were compared by the Student-Newman-Keul's multiple range test.

\section{RESULTS}

HPV sequence analyses. Partial amino acid sequences of the five HPV isolates obtained by TOFMS, compared with the sequence predicted by the Nebraska nucleotide analysis (U60141), are shown in Figure 1. The ID97 (P83549) and KS96
(P83550) isolates have been shown to have an additional 18 amino acid (aa) residues at the $\mathrm{N}$-termini and to be acetylated at this location, which was not predicted by the sequence of U60141 (20). This 18-aa extension and acetylation also was found to occur for the CO96 (P83664), UT96 (P83665), and TX96 (P83666) isolates. The sequences of CO96, UT96, and TX96 were almost identical to the previously published sequences for ID97 and KS97. The C-terminal 270-aa residues of the five HPV isolates are similar to those derived from U60141, but some differences were observed among the five HPV isolates. The ID97 and the UT97 isolates have subpopulations with either SSD or TSE at positions 53 to 55 ; all isolates had subpopulations with $\mathrm{E}, \mathrm{D}$, or $\mathrm{N}$ at position 204; isolates C096, ID97, and UT96 had I or T at position 234; and DSS or NST at positions 270 to 272 in ID97, CO96, and UT96. A final difference occurs at positions 285 and 286 for CO96, ID97, and UT96, which have subpopulations with ID or $\mathrm{T}$.

VPI of maize. When inoculated using VPI, all HPV isolates infected Spirit maize, but not all seed germinated following VPI, resulting in less than 100 plants in each experiment for each isolate. Levels of transmission ranged from $9.4 \%$ for CO96 to $32.6 \%$ for ID97 (Table 1). In contrast, when the resistant B73 was inoculated with the HPV isolates by VPI, lower levels of infection where noted for most isolates; the CO96 isolate was not infectious to B73, UT96 infected only one plant in the three experiments, and low levels of infection were noted for ID97 as well. However, the KS96 isolate infected significantly more B73 plants than the other four isolates.

WCM infestation of HPV-resistant B73 corn. All HPV isolates infected Westford barley when viruliferous WCM were used as vectors (Table 2). In contrast, when B73 maize was infested with WCM viruliferous for the CO96 isolate, none of the plants became infected, and only $2.7 \%$ of the B73 plants were infected using the TX96 isolate. However, the KS96 isolate again caused significantly higher levels of infection of B73 corn compared with CO96 and TX96, which were not different from each other. The levels of infection of B73 by these three HPV isolates were significantly less than those obtained using barley. Minimum and maximum ELISA values for leaf 4 of B73 corn infested with WCM viruliferous for C096, KS96, or TX96 were 0.022 to $0.029,0.083$ to 0.213 , and 0.089 to 0.157 , respectively, and those for leaf 4 of the barley controls were: 0.087 to $0.421,0.131$ to 0.407 , and 0.103 to 0.517 , respectively. The values for B73 infested with WCM viruliferous for $\mathrm{CO} 96$ were well under the 0.059 threshold set for

Table 1. Numbers and percent infection of 'Spirit' and 'B73' maize plants systemically infected by the High Plains virus (HPV) as indicated by symptoms and by testing positive in enzyme-linked immunosorbent assay following vascular puncture inoculation (VPI)

\begin{tabular}{|c|c|c|c|c|c|c|c|c|}
\hline \multirow[b]{2}{*}{ HPV isolate } & \multirow[b]{2}{*}{ Maize line } & \multicolumn{2}{|c|}{ Experiment 1} & \multicolumn{2}{|c|}{ Experiment 2} & \multicolumn{2}{|c|}{ Experiment 3} & \multirow[b]{2}{*}{ Average $(\%)^{\mathrm{z}}$} \\
\hline & & Number ${ }^{y}$ & Percent & Number ${ }^{y}$ & Percent & Number ${ }^{y}$ & Percent & \\
\hline $\mathrm{CO} 96$ & Spirit & $12 / 89$ & 13.4 & $6 / 85$ & 7.0 & $7 / 88$ & 7.9 & $9.4 \mathrm{CD}$ \\
\hline ID97 & Spirit & $20 / 68$ & 29.4 & $27 / 72$ & 37.5 & $26 / 84$ & 30.9 & $32.6 \mathrm{~A}$ \\
\hline KS96 & Spirit & $8 / 45$ & 17.2 & $9 / 63$ & 14.2 & $9 / 52$ & 17.3 & $16.2 \mathrm{BC}$ \\
\hline TX96 & Spirit & $19 / 69$ & 27.5 & $21 / 74$ & 28.3 & $26 / 76$ & 34.2 & $30.0 \mathrm{~A}$ \\
\hline UT96 & Spirit & $17 / 85$ & 20.0 & $11 / 76$ & 14.4 & $25 / 85$ & 29.4 & $21.3 \mathrm{AB}$ \\
\hline $\mathrm{CO} 96$ & B73 & $0 / 64$ & 0.0 & $0 / 62$ & 0.0 & $0 / 59$ & 0.0 & $0.0 \mathrm{~F}$ \\
\hline ID97 & B73 & $1 / 47$ & 2.1 & $0 / 39$ & 0.0 & $4 / 69$ & 5.8 & $2.6 \mathrm{EF}$ \\
\hline KS96 & B73 & $2 / 21$ & 9.5 & $2 / 31$ & 6.4 & $11 / 46$ & 23.9 & $13.3 \mathrm{BC}$ \\
\hline TX96 & B73 & $1 / 77$ & 1.2 & $4 / 70$ & 5.7 & $5 / 72$ & 6.9 & 4.6 DE \\
\hline UT96 & B73 & $0 / 73$ & 0.0 & $0 / 72$ & 0.0 & $1 / 66$ & 1.5 & $0.5 \mathrm{~F}$ \\
\hline
\end{tabular}

y Numerator represents number of HPV-infected plants and the denominator the total number of plants inoculated by VPI.

${ }^{\mathrm{z}}$ Treatments not having a letter in common are significantly different $(P \leq 0.05)$.

Table 2. Numbers and percent of Westford barley (WB) and 'B73' maize plants with systemic symptoms and symptom ratings for either the CO96, KS96, or TX96 isolates of the High Plains virus (HPV) following viruliferous wheat curl mite (WCM) infestation

\begin{tabular}{|c|c|c|c|c|c|c|c|c|}
\hline \multirow[b]{3}{*}{ HPV isolate } & \multirow[b]{3}{*}{ Host plant } & \multicolumn{4}{|c|}{ Numbers and percent infected plants } & \multirow[b]{3}{*}{$\mathbf{N}^{\mathbf{z}}$} & & \\
\hline & & & iment n & & & & \multicolumn{2}{|c|}{ Average symptom ratings ${ }^{x}$} \\
\hline & & 1 & 2 & 3 & Average $(\%)^{\mathrm{y}}$ & & Leaf no. 3 & Leaf no. 4 \\
\hline $\mathrm{CO} 96$ & WB & $10 / 15$ & $12 / 14$ & $11 / 14$ & $77.0 \mathrm{~B}$ & 33 & 2.9 & 2.6 \\
\hline KS96 & WB & $16 / 17$ & $21 / 21$ & $12 / 14$ & $93.3 \mathrm{~A}$ & 49 & 3.1 & 2.8 \\
\hline TX96 & WB & $19 / 24$ & $18 / 21$ & $16 / 20$ & $81.6 \mathrm{~B}$ & 53 & 2.8 & 2.3 \\
\hline CO96 & B73 & $0 / 25$ & $0 / 25$ & $0 / 25$ & $0.0 \mathrm{D}$ & 75 & 0.0 & 0.0 \\
\hline KS96 & B73 & $3 / 15$ & $11 / 25$ & $8 / 17$ & $37.0 \mathrm{C}$ & 22 & 2.9 & 1.3 \\
\hline TX96 & B73 & $0 / 25$ & $2 / 25$ & $0 / 25$ & $2.7 \mathrm{D}$ & 2 & 2.0 & 1.0 \\
\hline
\end{tabular}

${ }^{\mathrm{w}}$ Numerator represents the number of HPV infected plants and the denominator the total number of plants, each infested with $10 \mathrm{WCM}$.

${ }^{x}$ Rating: $0=$ no symptoms, $1=$ chlorotic spots $(\mathrm{CS}), 2=\mathrm{CS}$ with areas of mosaic, $3=$ moderate mosaic, $4=$ severe mosaic with occasional necrotic spots

y Number of plants with symptoms in the three experiments.

${ }^{\mathrm{z}}$ Treatments not having a letter in common are significantly different $(P \leq 0.05)$. 
a positive HPV reaction. In these experiments, only symptomatic plants tested positive for HPV in ELISA, and no plants were positive in ELISA for WSMV. WCM fed on healthy maize did not cause infection of the barley controls, nor did they develop symptoms to the brief exposure to the WCM. The symptoms for leaf 4 of B73 plants testing positive in ELISA were less severe than those of leaf 3 , with lesser differences observed between leaf 3 and 4 of the symptomatic barley plants (Table 2).

\section{DISCUSSION}

The present results demonstrate for the first time that the $32 \mathrm{np}$ of HPV isolates from a broad geographic range have differences in amino acid sequences (Fig. 1). An important finding was the observation that the amino acid sequences of HPV isolates CO96, UT96, and TX96, like KS96 and ID97 (20), had an 18-aa tract at the Nterminus not contained within the previously reported nucleotide sequence for the HPV $32 \mathrm{np}$ gene (J. S. Hall, S. G. Jensen, and R. C. French 1996; GenBank accession no. U60141). This difference was observed for all five isolates; therefore, it is likely that the U60141 sequence is incomplete. The latter sequence was determined from a cDNA of dsRNA extracted from ribonucleoproteins of plants infected by HPV and WSMV. Because dsRNA is notoriously difficult to reverse transcribe completely, it is likely that the cDNA did not represent the complete sequence. The use of VPI allowed us to establish pure cultures of HPV isolates, ensuring that proteins separated by SDS-PAGE were HPV specific. The coupling of VPI with TOFMS provided an excellent approach for determining the amino acid sequences and evidence for $\mathrm{N}$-terminal acetylation of the $32 \mathrm{np}$ of all five isolates and that certain isolates consist of subpopulations, a finding not reported previously. Interestingly, in contrast to CO96 and UT96, the KS96 isolate which had caused higher levels of infection of B73 corn was not shown to have subpopulations based upon the amino acid sequences as did C096 and UT96 (Fig. 1). However, several species of dsRNA have been identified with HPV (4); therefore, there may be nothing unusual in the lack of correlation between the 32-np sequence and the severity of a virus isolate.

We further tested the HPV isolates for variability using VPI of maize. We infected B73 with the TX96 isolate but only at low levels, while this isolate infected Spirit maize at much higher levels (Table 1). We used B73 maize because it was resistant (resistance defined as lack of systemic spread of the virus to upper leaves) to a Texas HPV isolate $(12,13)$. The fourth leaf of all plants testing positive in ELISA had symptoms. Plants without symptoms tested negative in ELISA. This finding is consistent with previous observations where symptoms were present on the lower leaves of B73 maize infected by a Texas HPV isolate, while the upper leaves were symptomless and negative for HPV in ELISA (12). The ID97 and UT96 isolates also infected B73 at low levels. In contrast, the KS96 isolate infected B73 at significantly higher levels, which were not different from those recorded for the Spirit control. Of particular interest was the observation that the $\mathrm{CO} 96$ isolate was not infectious to B73 by VPI, but was infectious to Spirit, although at low levels. The latter may indicate, for some HPV isolates, that the resistance manifested by lack of systemic spread of the virus may occur more rapidly for certain HPV isolates, resulting in apparently no infection.

The response of B73 to challenge by a pure culture of HPV was further determined using WCM infestation; the original report of resistance of B73 to HPV was demonstrated by these means $(12,13)$. Results using WCM viruliferous for the CO96, KS96, or TX96 isolates showed the same relationship among the isolates relative to levels of infection of B73 that were observed in the VPI experiment (Tables 1 and 2). The KS96 isolate caused significantly higher levels of infection than the TX 96 isolate in tests with viruliferous WCM (Table 2). Moreover, as observed for the VPI studies, the CO96 isolate failed to infect B73 when infested with viruliferous WCM. All HPV isolates were highly infectious to barley in these experiments, indicating that the WCM used to test B73 for susceptibility were viruliferous for CO96. HPV infection of barley using viruliferous WCM is in keeping with previous results $(15,16)$. The VPI and WCM tests with different HPV isolates confirm and extend previous reports that $\mathrm{B} 73$ has resistance to infection by HPV (12). In that study, although B73 was infected with HPV as a seedling, the resistance was shown to be associated with lack of systemic spread of the virus to the upper leaves of B73. However, our results show that not all HPV isolates, for example CO96, are infective in this maize line. However, isolate KS96 caused higher levels of infection of B73 than the other isolates whether inoculated by VPI or viruliferous WCM; however, our tests did not evaluate the levels of severity of infection of B73 beyond the fourth leaf stage. Symptom severity was observed to be much less for leaf 4 than leaf 3 of B73 for all isolates; therefore, it is possible that the inhibition of systemic spread of KS96 and TX96 was starting to occur by the fourth leaf (Table 2).

Our infection results showed similar patterns of infection of B73 whether inoculated by VPI or viruliferous WCM, suggesting that the VPI technique might be an alternate or supportive technique for evaluating HPV resistance in maize. No previous work has compared the efficacy of the two inoculation techniques.
In summary, new amino acid sequence data provided by TOFMS showed an 18-aa sequence at the $\mathrm{N}$-terminus of the $32 \mathrm{np}$ of all five HPV isolates, despite their wide geographic origins. Additional TOFMS observations showed that the N-termini of all HPV isolates are acetylated, that amino acid sequence differences exist between isolates, and that, for some isolates, subpopulations exist. Further, the present study showed that not all HPV isolates can infect the B73-resistant maize line when inoculated either by VPI or using the WCM vector; and, with the exception of one HPV isolate, infection by HPV occurred in only a few plants of B73. The results of the VPI technique provided similar results to those using WCM when challenging B73 in our tests, indicating that VPI may function as an alternative screening protocol for evaluating HPV resistance in maize.

\section{LITERATURE CITED}

1. Ahn, K.-K., Kim, K. S., Gergerich, R. C., and Jensen, S. G. 1998. High plains disease of corn and wheat: Ultrastructural and serological aspects. J. Submicrosc. Cytol. Pathol. 30:563571.

2. Clark, M. F., and Adams, A. N. 1977. Characteristics of the microplate method of enzymelinked immunosorbent assay for the detection of plant viruses. J. Gen. Virol. 34:475-483.

3. Forster, R. L., Seifers, D. L., Strausbaugh, C. A., Jensen, S. G., Ball, E. M., and Harvey, T. L. 2001. Seed transmission of the High plains virus in sweet corn. Plant Dis. 85:696-699.

4. Jensen, S. G., and Hall, J. S. 1995. Molecular characterization of a viral pathogen infecting maize and wheat in the high plains. (Abstr.) Phytopathology 85:1211.

5. Jensen, S. G., Lane, L. C., and Seifers, D. L. 1996. A new disease of maize and wheat in the high plains. Plant Dis. 80:1387-1390.

6. Keough, T., Youngquist, R. S., and Lacey, M. P. 1999. A method for high-sensitivity peptide sequencing using postsource decay matrix-assisted laser desorption ionization mass spectrometry. Proc. Natl. Acad. Sci. USA 96:71317136.

7. Laboda, A. V., Krutchinsky, A. N., Bromirski, M.., Ens, W., and Standing, K. G. 2000. A tandem quadrupole/time-of-flight mass spectrometer with a matrix-assisted laser desorption/ionization source: design and performance. Rapid Commun. Mass Spectrom. 14:1047-1057.

8. Laemmli, U. K. 1970. Cleavage of structural proteins during the assembly of head of bacteriophage T4. Nature 227:680-685.

9. Lane, L. C. 1986. Propagation and purification of RNA plant viruses. Methods Enzymol. 118:687-696.

10. Little, T. M., and Hills, R. J. 1978. Agricultural Experimentation: Design and Analysis. John Wiley \& Sons, New York.

11. Louie, R., and Seifers, D. L. 1996. Transmission of the High Plains pathogen by vascular puncture inoculation. (Abstr.) Phytopathology 86:S1.

12. Marcon, A., Kaeppler, S. M., and Jensen, S. G. 1997. Resistance to systemic spread of High plains virus and Wheat streak mosaic virus cosegregates in two F-2 populations inoculated with both pathogens. Crop Sci. 37:1923-1927.

13. Marcon, A., Kaeppler, S. M., and Jensen, S. G. 1997. Genetic variability among maize inbred lines for resistance to the High plains virusWheat streak mosaic virus complex. Plant Dis. 
81:195-198.

14. Seifers, D. L., Harvey, T. L., Kofoid, K. D., and Stegmeier, W. D. 1996. Natural infection of pearl millet and sorghum by wheat streak mosaic virus in Kansas. Plant Dis. 80:179-185.

15. Seifers, D. L., Harvey, T. L. Louie, R., Gordon, D. T., and Martin, T. J. 2002. Differential transmission of isolates of the High Plains virus by different sources of wheat curl mites. Plant Dis. 86:138-142.

16. Seifers, D. L., Harvey, T. L., Martin, T. J., and Jensen, S. G. 1997. Identification of the wheat curl mite as the vector of the High Plains virus of corn and wheat. Plant Dis. 81:1161-1166.

17. Seifers, D. L., Harvey, T. L., Martin, T. J., and Jensen, S. G. 1998. A partial host range of the High Plains virus of corn and wheat. Plant Dis.
82:875-879.

18. Seifers, D. L., Salomon, R., Marie-Jeanne, V., Alliot, B., Signoret, P., Haber, S., Loboda, A., Ens, W., She, Y.-M., and Standing, K. G. 2000. Characterization of a novel potyvirus isolated from maize in Israel. Phytopathology 90:505513.

19. She, Y. M., Haber, S. Seifers, D. L., Loboda, A., Chernuschevich, I., Pereault, H. Ens, W., and Standing, K. G. 2001. Determination of the complete amino acid sequence for the coat protein of Brome mosaic virus by time-offlight mass spectrometry. J. Biol. Chem. 276:20039-20047.

20. She, Y.-M., Seifers, D. L., Haber, S., Ens, W., and Standing, K. G. 2004. Characterization of the agent of 'High Plains Disease' :Mass spec- trometry determines the sequence of the disease-specific protein. J. Biol. Chem: 279:488494.

21. She, Y-M., Wang, G. Q., Loboda, A., Ens, W Standing, K. G., and Burczynski, F. J. 2002. Sequencing of rat liver cytosolic proteins by matrix-assisted laser desorption ionizationquadrupole time of flight mass spectrometry following electrophoretic separation and extraction. Anal. Biochem. 310:137-147.

22. Skare, J. M., Wijkamp, I., Rezende, J., Michels, G., Rush, C. Scholthof, K.-B. G., and Scholthof, H. B. 2003. Colony establishment and maintenance of the eriophyid wheat cur mite Aceria tosichella for controlled transmission studies on a new virus-like pathogen. J. Virol. Methods 108:133-137. 